\title{
Heavy Metal Cadmium Tolerance on the Growth Characteristics of Industrial Hemp (Cannabis sativa L.) in China
}

\author{
Yin Tang ${ }^{1, \text { a }}$, Qibei Bao ${ }^{2, \mathrm{~b},{ }^{*}}$, and Guangming Tian ${ }^{1, \mathrm{c}, ~ *}$,Kejie $\mathrm{Fu}^{2, \mathrm{~d}}$,Haixiang \\ Cheng ${ }^{3, e}$
}

${ }^{1}$ Block B 273 in the College of Environmental \& Resource Science, Zhejiang University, HangZhou, 310029, P.R. China
${ }^{2}$ Ningbo Academy of Science \& Technology for Inspection \& Quarantine, Ningbo, 315100, P.R. China
${ }^{3}$ College of Chemistry and Materials Engineering of Quzhou University, Quzhou, 324000, P.R. China

a21314066@zju.edu.cn, bbaoqibei@126.com, 'cgmtian@zju.edu.cn, dfkjciq@126.com,

ehaixiangcheng@zju.edu.cn

*corresponding authors

Keywords: cadmium stress; industrial hemp; photosynthetic characteristics; chlorophyll fluorescence

Abstract. The effects of different concentrations of cadmium $(\mathrm{Cd})$ on the growth physiological parameters of industrial hemp, including growth, the photosynthetic characteristics, the chlorophyll fluorescence and so on, were studied with hydroponic greenhouse experiments. The results showed that with the increase of $\mathrm{Cd}$ concentration, the levels of chlorophyll $\mathrm{a}$, chlorophyll $\mathrm{b}$ and carotenoids in hemp leaves decreased, and the decreasing rates were in the following order: carotenoid $>$ chlorophyll $b>$ chlorophyll a. For the plants under Cd stress, net photosynthetic rate (Pn), transpiration rate (Tr) and stomatal conductance (Gs) showed a downward tendency as the concentration of $\mathrm{Cd}$ increased, while intercellular $\mathrm{CO}_{2}$ concentration (Ci) increased slowly. During the stress process, the maximum primary photochemical efficiency $(\mathrm{Fv} / \mathrm{Fm})$ and the photosynthetic electron transport rate (ETR) decreased. The actual quantum yield (Yield) and the photochemical quenching coefficient (qP) showed an apparent middle low point at $50 \mu \mathrm{mol} / \mathrm{L}$, increased with increasing $\mathrm{Cd}$ concentration, and then decreased rapidly after the concentration reached $75 \mu \mathrm{mol} / \mathrm{L}$. The non-photochemical quenching coefficient (NPQ) reached its maximum value at Cd level of $50 \mu \mathrm{mol} / \mathrm{L}$. The $\mathrm{Cd}$ stress has significant impacts on the photosynthetic mechanism of industrial hemp. With a high concentration of $\mathrm{Cd}(>75$ $\mu \mathrm{mol} / \mathrm{L})$, photosynthetic metabolism of hemp was inhibited and damaged. The Cd tolerance of hemp was related to the protection mechanism of chlorophyll a. Under Cd stress, there was a self-protection mechanism to reduce the impact of $\mathrm{Cd}$ stress on the photosynthesis in hemp via sacrificing the carotenoids to protect the chlorophyll in hemp leaves.

\section{Introduction}

Cadmium $(\mathrm{Cd})$ is one of the most bio-toxic heavy metals, and become infamous due to the outbreak of Itai-itai disease. In recent years, researchers have conducted numerous studies on the toxicity of Cd on plants and the mechanism of Cd tolerance in plants. These researches have mainly focused on the effects of $\mathrm{Cd}$ on the growth, physiology, biochemistry, cell structure, photosynthesis, enzyme activity, and so on[1-2]. The photosynthesis is the most important process of assimilation and the foundation of providing material supports for the growth and development of plants. Many current studies about the effects of Cd stress on the photosynthesis have showed that $\mathrm{Cd}$ exhibits a significant inhibition on the photosynthesis, however, the specific mechanism is still controversial[3-6]. Industrial hemp is a species of cannabis plants with a tetrahydrocannabinol (THC) content of less than $0.3 \%$, and is commonly called Han-ma in China. It is an annual herb belonging to the genus CannabisL. in the family Cannabaceae of the order Urticales in the class Magnoliopsida. Its characteristics include large biomass, strong resistance, fast growth, easy to grow and manage, and provides a wide range of 
applications in the implementation of the phytoremediation for low-concentration polluted areas [7-8].

Currently the existing studies on the relationship between $\mathrm{Cd}$ stress and plant photosynthesis is mainly concentrated in the areas of non-tolerant plants. However, among those studies about the uptake mechanism of tolerant plants with large biomass, the researches about the influences of $\mathrm{Cd}$ stress on plant photosynthetic characteristics and parameters of chlorophyll fluorescence kinetics are still relatively rare. In this paper, the nutrient solution culture experiments were used to study the changes in the photosynthetic characteristics and chlorophyll fluorescence parameters of industrial hemp under different levels of cadmium stress. The aim is to investigate the mechanism of $\mathrm{Cd}$ tolerance of industrial hemp, and to further provide a theoretical basis for promoting the phytoremediation in environmental $\mathrm{Cd}$ pollution.

\section{Materials and methods}

Experiment materials. The selected hemp seeds for the experiments were 'Yun Ma \#1', which was widely planted in Yunnan province in China. Seeds were provided by th Yunnan Hemp Industrial Investment Holding Co., Ltd.

Experimental design.Plump hemp seeds were selected and rinsed with ultrapure water, then soaked in ultrapure water for 12 hours. Subsequently, the seeds were placed on a 10-mesh sieve with double layers of gauze about $25^{\circ} \mathrm{C}$ for the germination. During the germination, the gauze was kept wet. After about six to seven days, once two true leaves were present, strong and consistent growing hemp seedlings were selected and transferred to10-L plastic boxes. The seedlings were first cultured in $1 / 2$ Hoagland's nutrient solution and aeration was maintained to prevent root decay. Light with an intensity 50001x was supplied for 12 hours per day and temperature was controlled at $25-30^{\circ} \mathrm{C}$. After another five days, the seedlings were grown in full Hoagland's nutrient solution for seven days, $\mathrm{CdCl}_{2} \cdot 2.5 \mathrm{H}_{2} \mathrm{O}$ was added to the nutrient solution, and five $\mathrm{Cd}^{2+}$ concentration gradients were set as 0 , $25,50,75$, and $100 \mu \mathrm{mol} / \mathrm{L}$, respectively[9-11].There were three parallel sets in each treatment, and each of them included 20 plants. On the 30th day of Cd stress treatment, the biomass of hemp plant (including root, stem and leaf), and the parameters of photosynthesis and chlorophyll fluorescence were measured.

Measuring methods.Determination of biomass: After removing the plant, roots were first eluted with $5 \mathrm{mmol} / \mathrm{L} \mathrm{CaCl}_{2}$, rinsed with deionized water and dried with filter paper. The plant height and root length were measured for each plant under different treatment conditions. Then the fixation of aerial parts and roots were carried out at $105^{\circ} \mathrm{C}$ for 15 minutes and sample was dried at $80^{\circ} \mathrm{C}$ to constant weight. The dry weights of both parts were considered as the biomass of the plant.

Determination of chlorophyll content: Fresh leaves with a weight of 0.2 gram were selected from the second and third fully expanded hemp leaves and cut into pieces with their veins removed. The leaf sample together with a small amount of quartz sand and $3 \mathrm{~mL}$ of $80 \%$ acetone were grinded into a homogenate, rinsed with $7 \mathrm{~mL}$ of acetone and transferred to a centrifuge tube. After being centrifuged at $4000 \mathrm{rpm}$ for 10 minutes, the supernatant of the leaf sample was poured into a cuvette for measurements. Using $80 \%$ acetone as a control background, the absorbance values were measured at wavelengths of $665 \mathrm{~nm}, 649 \mathrm{~nm}$ and $470 \mathrm{~nm}$, respectively[11]. The chlorophyll concentration was then calculated with formula[12].

Determination of photosynthetic parameters: After 30d treatment, the net photosynthetic rate $(\mathrm{Pn})$, the stomatal conductance $(\mathrm{Gs})$, the intercellular $\mathrm{CO}_{2}$ concentration $(\mathrm{Ci})$ and the transpiration rate (Tr) of fully expanded hemp leaves were measured between 9:30-11:00 with a Li-6400 portable photosynthesis system (Li-Cor Biosciences, USA). The photon flux density was $1000 \mu \mathrm{mol} /\left(\mathrm{m}^{2} \cdot \mathrm{s}\right)$. Determination of chlorophyll fluorescence parameters: A chlorophyll fluorescence imaging system (Imaging-PAM Chlorophy II Fluorometer,WALZ,Germany) was used to measure the chlorophyll fluorescence of the plants. After 30-minute dark adaption for living plants, the uppermost fully expanded leaves with an appropriate size were selected. The kinetic curves of the chlorophyll fluorescence parameters for each leaf could be measured in the Kinetics window of the software and 
the corresponding data can be directly exported from the Report window. The related chlorophyll fluorescence parameters included the maximum primary photochemical efficiency ( $\mathrm{Fv} / \mathrm{Fm}$ )of photosystem (PS) II, the $\Phi_{\text {psII }}$ actual yield (Yield), the photochemical quenching coefficient (qP), the non-photochemical quenching coefficient (NPQ) and the photosynthetic electron transport rate (ETR). Each measurement was repeated three times.

\section{Data analysis}

The experimental data was processed and analyzed with Microsoft Excel and SPSS17.0.

\section{Results}

Biomass of hemp. The stem length and biomass of all the plants that were treated under $\mathrm{Cd}$ stress for 30 days were significantly lower than those of control group (Table 1), indicating that Cd has a severe inhibition on the growth of hemp. The growth inhibition of Cd stress on the aerial part of hemp plants was relatively more significant than that on the root part. Low concentration of $\mathrm{Cd}$ had a growth-stimulating effect on the hemp root; the root length reached its maximum when treated with $\mathrm{Cd}$ at a concentration of $50 \mu \mathrm{mol} /$. With $\mathrm{Cd}$ concentration continued to increase, the root length was greatly reduced. Compared to control group, the biomasses of hemp plants treated with $\mathrm{Cd}$ at concentrations of $25,50,75$, and $100 \mu \mathrm{mol} / \mathrm{L}$ decreased by $33.61 \%, 42.65 \%, 57.91 \%$, and $58.99 \%$, respectively. With the increase of Cd concentration, the inhibitory effect of $\mathrm{Cd}$ stress on the growth of hemp gradually increased.

Table1: Growth parameters of hemp with different cadmium level

\begin{tabular}{cccc}
\hline $\begin{array}{c}\text { Cd concentration } \\
\left(\mu \mathrm{mol} \cdot \mathrm{L}^{-1}\right)\end{array}$ & $\begin{array}{c}\text { Stem length } \\
(\mathrm{cm})\end{array}$ & $\begin{array}{c}\text { Root length } \\
(\mathrm{cm})\end{array}$ & $\begin{array}{c}\text { Biomass } \\
(\mathrm{g})\end{array}$ \\
\hline 0 & $49.96 \pm 3.14 \mathrm{a}$ & $12.94 \pm 2.11 \mathrm{ab}$ & $28.77 \pm 3.51 \mathrm{a}$ \\
25 & $28.03 \pm 1.16 \mathrm{~b}$ & $13.77 \pm 2.10 \mathrm{ab}$ & $19.10 \pm 2.37 \mathrm{~b}$ \\
50 & $20.04 \pm 1.29 \mathrm{c}$ & $14.63 \pm 1.25 \mathrm{a}$ & $16.50 \pm 1.93 \mathrm{c}$ \\
75 & $17.10 \pm 0.68 \mathrm{~d}$ & $9.63 \pm 2.30 \mathrm{~b}$ & $12.11 \pm 1.87 \mathrm{~d}$ \\
100 & $15.26 \pm 1.08 \mathrm{e}$ & $8.67 \pm 1.68 \mathrm{~b}$ & $11.80 \pm 2.02 \mathrm{~d}$ \\
\hline
\end{tabular}

Date in the same line followed different small letters mean significant difference at $\mathrm{p}=0.05$ level

Chlorophyll content. As shown in Table 2, Cd stress significantly reduced the chlorophyll content in hemp leaves. Compared to control group, the contents of chlorophyll a, chlorophyll b and carotenoids in treatment group were all significantly reduced with increasing $\mathrm{Cd}$ concentration. When $\mathrm{Cd}$ concentrations were $25,50,75$, and $100 \mu \mathrm{mol} / \mathrm{L}$, the contents of chlorophyll a in treatment group decreased by $26.52 \%, 35.68 \%, 41.62 \%$, and $54.57 \%$, respectively, the corresponding contents of chlorophyll b in treatment group decreased by $25.06 \%, 33.67 \%, 43.96 \%$, and $58.60 \%$, respectively; and the corresponding contents of carotenoids in treatment group decreased by $28.12 \%, 52.55 \%$, $81.37 \%$, and $90.83 \%$, respectively.

Table 2: Chlorophyll content of hemp leaves with different cadmium level

\begin{tabular}{cccc}
\hline $\begin{array}{c}\text { Cd } \\
\begin{array}{c}\text { oncentration } \\
\left(\mu \mathrm{mol} \cdot \mathrm{L}^{-1}\right)\end{array}\end{array}$ & $\begin{array}{c}\text { Content of } \\
\text { chlorophyll a } \\
(\mathrm{mg} / \mathrm{g} \text { fresh weight })\end{array}$ & $\begin{array}{c}\text { Content of } \\
\text { chlorophyll b } \\
(\mathrm{mg} / \mathrm{g} \text { fresh weight })\end{array}$ & $\begin{array}{c}\text { Content of } \\
\text { carotenoid } \\
(\mathrm{mg} / \mathrm{g} \text { fresh weight })\end{array}$ \\
\hline 0 & $1.9590 \pm 0.1404 \mathrm{aA}$ & $1.4733 \pm 0.4094 \mathrm{aA}$ & $1.7247 \pm 0.3997 \mathrm{aA}$ \\
25 & $1.4394 \pm 0.1251 \mathrm{bB}$ & $1.104 \pm 0.0182 \mathrm{bB}$ & $1.2396 \pm 0.1686 \mathrm{bB}$ \\
50 & $1.2601 \pm 0.2263 \mathrm{cC}$ & $0.9772 \pm 0.0498 \mathrm{cC}$ & $0.8184 \pm 0.0763 \mathrm{cB}$ \\
75 & $1.1437 \pm 0.149 \mathrm{dD}$ & $0.8257 \pm 0.0203 \mathrm{dD}$ & $0.3214 \pm 0.0511 \mathrm{dD}$ \\
100 & $0.8898 \pm 0.0888 \mathrm{dD}$ & $0.610 \pm 0.0102 \mathrm{eD}$ & $0.1582 \pm 0.0201 \mathrm{eE}$ \\
\hline
\end{tabular}

Date in the same line followed different small letters mean significant difference at $\mathrm{p}=0.05$ level

Date in the same line followed different capital letters mean significant difference at $\mathrm{p}=0.01$ level 
Photosynthetic characteristic parameters. The experimental results (Table 3 ) indicated that the $\mathrm{Cd}$ stress significantly affected the photosynthetic rate of hemp leaves. The values of $\mathrm{Pn}, \mathrm{Tr}, \mathrm{Gs}$, and $\mathrm{Ci}$ showed significant differences at different $\mathrm{Cd}$ concentrations $(\mathrm{P}<0.05)$. The $\mathrm{Pn}, \mathrm{Tr}$, and Gs values all showed a downward tendency with increasing $\mathrm{Cd}$ concentration, while the $\mathrm{Ci}$ value showed an opposite trend. After treated with $\mathrm{Cd}$ at concentrations of $25,50,75$, and $100 \mu \mathrm{mol} / \mathrm{L}$ for 30 days, when compared to the control group, the Pn values of treated plants decreased by $18.9 \%, 30.5 \%$, $43.0 \%$, and $65.3 \%$, respectively. The $\operatorname{Tr}$ values of treated plants decreased by $14.8 \%, 26.7 \%, 43.9 \%$, and $71.1 \%$, respectively. The Gs values of treated plants decreased by $14.7 \%, 31.2 \%, 39.2 \%$, and $59.5 \%$, respectively. The $\mathrm{Ci}$ values of treated plants increased by $2.8 \%, 6.7 \%, 9.9 \%$, and $18.2 \%$, respectively.

Table 3: Gas exchange parameters for hemp leaves treated under different cadmium level

\begin{tabular}{|c|c|c|c|c|}
\hline $\begin{array}{c}\mathrm{Cd} \\
\text { Concentration } \\
\left(\mu \mathrm{mol} \cdot \mathrm{L}^{-1}\right)\end{array}$ & $\begin{array}{c}\text { Net } \\
\text { photosynthesis rate } \\
(\mathrm{Pn}) \\
\left(\mu \mathrm{mol} \cdot \mathrm{m}^{-2} \cdot \mathrm{s}^{-1}\right)\end{array}$ & $\begin{array}{l}\text { Transpiration ratio } \\
\quad(\mathrm{Tr}) \\
\quad\left(\mathrm{mmol} \cdot \mathrm{m}^{-2} \cdot \mathrm{s}^{-1}\right)\end{array}$ & $\begin{array}{l}\text { Stomatal conductance } \\
\quad(\mathrm{Gs}) \\
\left(\mathrm{mmol} \cdot \mathrm{m}^{-2} \cdot \mathrm{s}^{-1}\right)\end{array}$ & $\begin{array}{c}\text { Intercellula } \\
\text { r CO2 } \\
\text { concentration } \\
(\mathrm{Ci}) \\
\left(\mu \mathrm{L} \cdot \mathrm{L}^{-1}\right)\end{array}$ \\
\hline 0 & $15.133 \pm 0.203 a$ & $2.630 \pm 0.050 \mathrm{a}$ & $0.135 \pm 0.003 a$ & $253 \pm 2.1565 \mathrm{e}$ \\
\hline 25 & $12.267 \pm 0.203 b$ & $2.243 \pm 0.072 b$ & $0.115 \pm 0.003 b$ & $260 \pm 3.0551 \mathrm{~d}$ \\
\hline 50 & $10.521 \pm 0.4799 c$ & $1.810 \pm 0.036 \mathrm{c}$ & $0.099 \pm 0.001 \mathrm{c}$ & $270 \pm 2.5167 \mathrm{c}$ \\
\hline 75 & $8.627 \pm 0.2525 \mathrm{~d}$ & $1.600 \pm 0.065 \mathrm{~d}$ & $0.0757 \pm 0.003 \mathrm{~d}$ & $278 \pm 5.0326 \mathrm{~b}$ \\
\hline 100 & $5.256 \pm 0.1246 \mathrm{e}$ & $1.064 \pm 0.041 \mathrm{e}$ & $0.039 \pm 0.002 \mathrm{e}$ & $299 \pm 3.1458 \mathrm{a}$ \\
\hline
\end{tabular}

Date in the same line followed different small letters mean significant difference at $\mathrm{p}=0.05$ level

Chlorophyll fluorescence parameters. Figure. 1 shows the effect of $\mathrm{Cd}$ stress on chlorophyll fluorescence parameters of hemp leaves.In fluorescence analysis, the $\mathrm{Fv} / \mathrm{Fm}$ reflects the photochemical conversion efficiency of PS II. The changes of $\mathrm{Fv} / \mathrm{Fm}$ was small at low $\mathrm{Cd}$ concentration $(25 \mu \mathrm{mol} / \mathrm{L})$, and a significant decline of $\mathrm{Fv} / \mathrm{Fm}$ was observed at a relatively high $\mathrm{Cd}$ concentration $(100 \mu \mathrm{mol} / \mathrm{L})$. Compared to the control group, the $\mathrm{Fv} / \mathrm{Fm}$ values of hemp plants treated with $\mathrm{Cd}$ at concentrations of $25,50,75$, and $100 \mu \mathrm{mol} / \mathrm{L}$ decreased by $15.4 \%, 31.1 \%, 31.9 \%$, and $43.5 \%$, respectively.

The Yield reflects the actual primary energy capture efficiency of PS II in the case that some reaction centers are closed. A higher PS II value indicates a higher energy conversion rate and a stronger PS II activity. For those hemp plants treated with the Cd concentration in a range of 0 50 $\mu \mathrm{mol} / \mathrm{L}$, as the $\mathrm{Cd}$ concentration increased, the Yield declined to reach a middle low point at 50 $\mu \mathrm{mol} / \mathrm{L}$, then peaked at $75 \mu \mathrm{mol} / \mathrm{L}$. In the range of $75 \sim 100 \mu \mathrm{mol} / \mathrm{L}$, Yield quickly declined to the lowest point as the $\mathrm{Cd}$ concentration increased.

The qP indicates the level of photochemical chlorophyll fluorescence quenching, reflecting the portion of the energy used for photochemical electron transfer in the light energy captured by PS II antenna pigments. The trend of the changes in $\mathrm{qP}$ was similar to that of Yield, showed a V-shaped bottom at $\mathrm{Cd}$ concentration of $50 \mu \mathrm{mol} / \mathrm{L}$, and slightly increased with increasing Cd concentrations, followed by a rapid decline after $75 \mu \mathrm{mol} / \mathrm{L}$.

The NPQ reflects the portion of the energy that cannot be used for photochemical electron transfer and is dissipated as heat in the light energy captured by PS II antenna pigments. NPQ showed an upward trend as $\mathrm{Cd}$ concentration increased from $0 \mu \mathrm{mol} / \mathrm{L}$ to $50 \mu \mathrm{mol} / \mathrm{L}$, and decreased rapidly when the $\mathrm{Cd}$ concentration increased from $50 \mu \mathrm{mol} / \mathrm{L}$ to $100 \mu \mathrm{mol} / \mathrm{L}$.

The ETR reflects the photosynthetic quantum transfer efficiency. ETR and Fv/Fm exhibited a similar trend, showing a significant decreasing trend with increasing $\mathrm{Cd}$ concentration. 

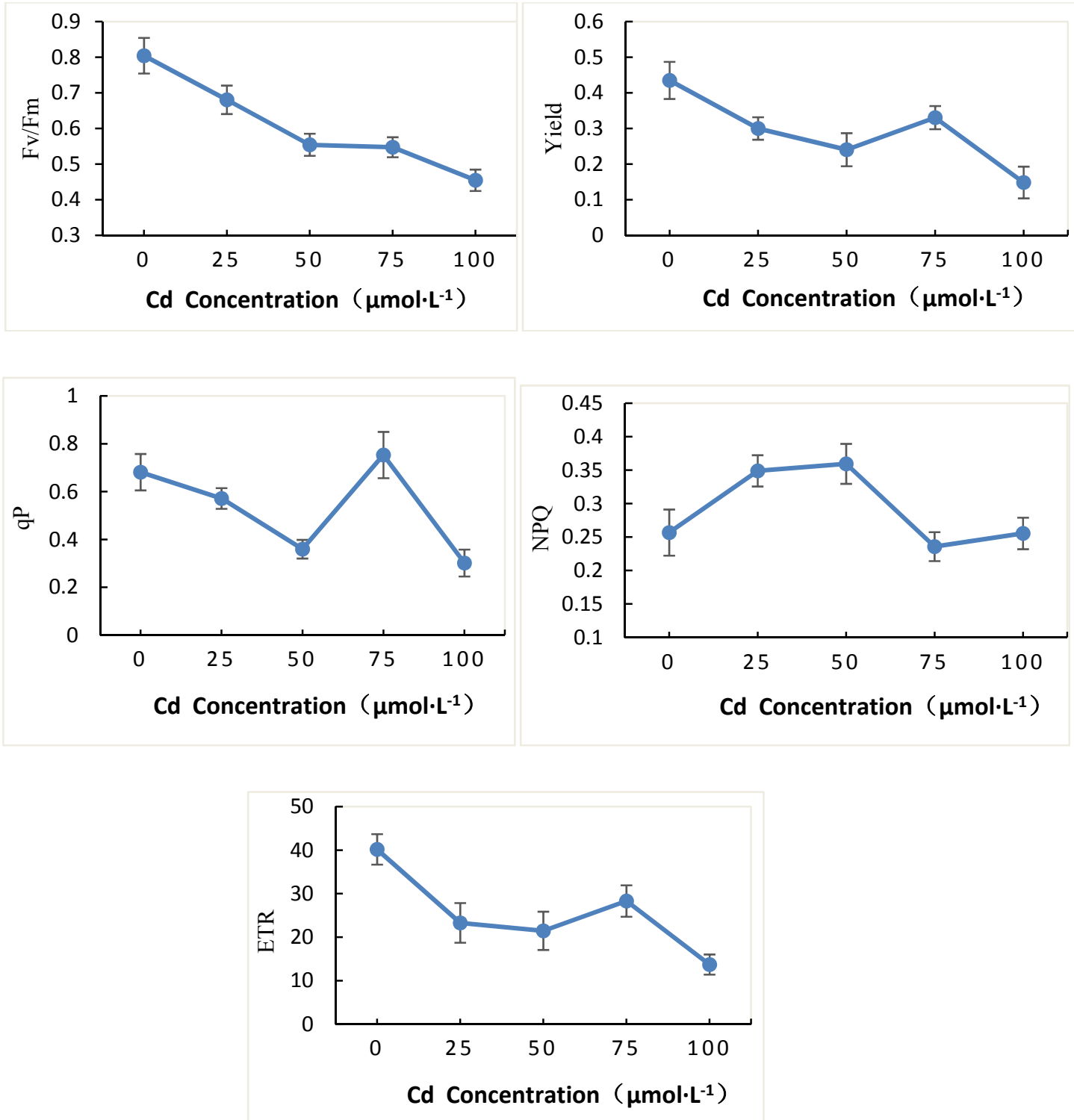

Figure 1:Effect of different cadmium level on chlorophyll fluorescence parameters in hemp leaves

\section{Discussion}

A decline of chlorophyll content in plant leaves is one of the most common symptoms when the plant is treated at high concentrations of $\mathrm{Cd}$. One reason is that the high concentration of $\mathrm{Cd}$ inhibits the absorption of some elements such as $\mathrm{Mg}$ and Fe that are essential for the synthesis of chlorophyll, thus blocking the chlorophyll synthesis [12-13]. In addition, the high concentration of Cd causes the changes in the structure of chlorophyll a, thus affecting its normal function. The chlorophyll content has a direct impact on the photosynthetic rate of plants. Chlorophyll a makes a more important contribution to the photosynthesis process; the increases of chlorophyll a/chlorophyll b contents favor the absorption and the conversion of light energy as well as the carbon oxidation in plants.[14] In this experiment, the results showed that high concentrations of $\mathrm{Cd}$ significantly reduced the contents of chlorophyll a, chlorophyll $\mathrm{b}$ and carotenoids. The carotenoid content was first affected, which may be due to the self-protection mechanism of hemp plants and related to their Cd tolerance.

After 30-day Cd treatment, the Pn and Gs values continued to decline, but the $\mathrm{Ci}$ value increased significantly, indicating that the main factor of photosynthetic decline is non-stomatal limitation, which is also supported by the chlorophyll content and chlorophyll fluorescence parameters.

PS II is not only an important part of the photosynthesis process, but also an important site to explore the heavy metal stress on plants. Studies have shown that heavy metal stress can reduce the 
activity of PS II[15]. The results of this study showed that Cd significantly inhibited the PS II activity, and the Fv/Fm and ETR values were significantly reduced. Under normal physiological conditions, the change of $\mathrm{Fv} / \mathrm{Fm}$ was insignificant, but $\mathrm{Fv} / \mathrm{Fm}$ decreased when plants were under heavy metal stress. Therefore, Fv/Fm is an important parameter to monitor the quality of environment for plant growth, and a good indicator to show the photosynthetic inhibition induced by heavy metal stress on plants within a short time[16]. In this experiment, initially, the $\mathrm{qP}$ decreased significantly and the NPQ increased significantly, suggesting that the damage to PS II primary photochemical reaction induced by a low concentration of Cd was not severe and PS II was protected by leaves through effective heat dissipation mechanism. However, with a significant increase in the Cd concentration, the NPQ decreased and other fluorescence parameters also exhibited a significant decline, indicating that PS II primary photochemical reaction has been severely damaged. In this process, the protection mechanism of non-photochemical quenching plays a significant role, which may be related to the $\mathrm{Cd}$ tolerance of hemp plants.

\section{Conclusions}

Cd stress can have significant impacts on the photosynthetic mechanism of industrial hemp, causing a reduction of the chlorophyll content, part of the gas exchange parameters and chlorophyll fluorescence parameters. Under the treatment with a high concentration of $\mathrm{Cd}$, the process of photosynthetic metabolism in hemp plants was inhibited and damaged. The Pn value decreased due to the non-stomatal limiting factors. At high $\mathrm{Cd}$ concentration, the reducing rates of three types of photosynthetic pigments in hemp leaves were in the following order: carotenoids $>$ chlorophyll $b>$ chlorophyll a. This may be a self-protection mechanism of hemp plants to protect chlorophylls via sacrificing carotenoids, thus reducing the influences of $\mathrm{Cd}$ stress on the photosynthesis process.

\section{Acknowledgements}

This work was supported by The Natural Science Foundation of Zhejiang Province, China (No. LQ13B070003), Technology Research Foundation of General Administration of Quality Supervision, Inspection and Quarantine of the People's Republic of China (No. 2014IK178), and The Natural Science Foundation of Zhejiang Province, China (No. LQ14E080012).

\section{References}

[1] S.A. Hasan, Q. Fariduddin, B. Ali, S. Hayat, A. Ahmad: Journal Of Environmental Biology / Academy Of Environmental Biology, India, Vol.30(2) (2009), p.165-174.

[2] S.G. Xue, Y.X. Chen, Y M. Luo, D.R. Roger, Q. Lin: Acta Ecologica sinica, Vol 41(6) (2004), p.879-895. In Chinese

[3] J.N. Liu, Q.X. Zhou, T. Sun, X.F. Wang: Chinese Journal of Applied Ecology, Vol 18(7) (2007), p.1617-1623. In Chinese

[4] S.G. Xue, Y.E. Sheng, F. Zhou: Acta Ecologica Sinica, Vol 28(12) (2008), p.6344-6347. In Chinese

[5] L. Ferroni, C. Baldisserotto, M.P. Fasulo, A. Pagnoni, S. Pancaldi: (2004):Protoplasma, Vol 224(3-4) (2004), p.167-77

[6] Q B Chen, L H Yu, M Yang,W Xu: Hemp cultivation and development plan (University of Electronic Science and technology Press, Chengdu, 1993)

[7] S. Citterio, A. Santagostino, P, Fumagalli: Plant \& Soil, Vol 256(2) (2003), p.243-252.

[8]G.R Shi: Screening of heavy metal-tolerant energy plants and their adaptability to metal stress in Chinese (Nanjing Agricultural University, Nanjing, 2009) In Chinese. 
[9]D D Wei: The influence of plant growth promoting bacteria (PGPB) on the growth of hemp seedling under heavy metal stress (Nanjing Agricultural University, Nanjing, 2012) In Chinese.

[10] J.S. Liu, H. Shi, Y.Y. Li: Research of Soil and Water Conservation, Vol 18(5) (2011), p.187-190. In Chinese.

[11] X.K. Wang: Experimental principle and technology of plant physiology biochemistry (Higher education press, Beijing, 2007).

[12] P. Linger, A. Ostwald, J. Haensler: BiologiaPlantarum, Vol 49(4) (2005), p.567-576.

[13] J. Feng, Q. Shi, X. Wang: Scientia Horticulturae, Vol 123 (2010), p.521-530.

[14] S.M. Prasad, J.B. Singh, L.C. Rai, H.D. Kumar: FEMS Microbiology Letters, Vol 82 (1991), p.95-100.

[15] P. Linger, A. Ostwald, J. Haensler: Biologia Plantarum, Vol 49(4) (2005), p.567-576.

[16] G H Krause, E Weis: The Basics Annual Review of Plant Physiology and Plant Molecular Biology, Vol 42 (1991), p. 313-349. 